\title{
AS RESISTÊNCIAS AO PODER EM MICHEL FOUCAULT
}

\author{
Guilherme Castelo BRANCO ${ }^{1}$
}

- RESUMO: Ainda pouco estudada, a última fase do pensamento de Michel Foucault traz contribuições inegáveis ao debate ético e político de nossa época, sobretudo por enfatizar o papel do indivíduo e das coletividades nas lutas de transformação das estruturas de poder ora vigentes. Os modos de ser das lutas de resistência, sua importância no quadro referencial do último Foucault, revelam uma dimensão política antes insuspeitada em sua obra. Essa dimensão, para além da analítica do poder, concede aos pequenos e múltiplos movimentos de contestação papel importante e decisivo para o futuro da vida sociopolítica, fora do quadro programático dos partidos políticos estabelecidos e das formas de ação instituídas. O que nos leva a retomar, a partir de novos referenciais teóricos, a discussão sobre o potencial revolucionário ainda possível da atualidade.

- PALAVRAS-CHAVE: Resistência; poder; liberdade; Foucault; filosofia contemporânea.

Nosso objetivo, neste trabalho, é elucidar conceitos fundamentais presentes na última fase do pensamento de Michel Foucault. Gostaríamos de abordar, inicialmente, aspectos da seqüência cronológica da obra de Michel Foucault, com o objetivo de facilitar a compreensão dessa última fase, ainda pouco conhecida, do filósofo francês, cujo escopo, na leitura que propomos, é eminentemente filosófico-político. Nosso cuidado em tratar das descontinuidades internas da obra de Foucault, por-

1 Departamento de Filosofia - UFRJ - 20550-900 - Rio de Janeiro - RJ. 
tanto, é o de construir um quadro diferencial em que muitas confusões possam se desfazer, uma vez que não são poucos os que crêem, equivocadamente, que a analítica do poder é o ponto definitivo e final das reflexões do pensador contemporâneo.

Conhecido do grande público cultivado desde a publicação do Les mots et les choses (1966), Foucault suscitou a renovação da epistemologia das ciências humanas e biomédicas e trouxe uma série de contribuições, nessa fase, ao debate histórico-crítico, de inegável alcance no domínio da teoria das ciências. Entretanto, gostaríamos de chamar a atenção para suas idéias quanto à política, que estão apresentadas em sua primeira entrevista de maior porte (1967), onde Foucault, debatendo com um entrevistador assumidamente humanista e polemizador (P. Caruso), defende uma posição decididamente oposta. $\mathrm{O}$ calor da entrevista, farta de ironias, não deixa de levar o debate a questões diversas, como a relação entre política, ética, controle e burocracia. Passemos a fragmentos escolhidos do texto, respostas de Foucault (1994, p.616), que à época é francamente partidário das teorias sistêmicas: "na realidade, os problemas que são levantados aos que fazem política, são problemas como o de saber se deve-se deixar aumentar o índice de crescimento demográfico, se é melhor apoiar a indústria pesada ou a pequena indústria, se o consumo, o aumento de consumo podem apresentar numa conjuntura determinada vantagens econômicas ou não. Eis os problemas políticos. Neste plano, jamais encontramos homens". Mais à frente, Foucault (1994, p.619) acrescenta:

A humanidade é uma espécie dotada de um sistema nervoso tal que, até determinado ponto, pode controlar seu próprio funcionamento. É claro que essa possibilidade de controle suscita continuamente a idéia de que a humanidade deva ter uma finalidade. Descobrimos este fim na medida em que temos a possibilidade de controlar nosso próprio funcionamento ... mas a humanidade, na realidade, não dispõe de nenhuma finalidade; ela funciona; ela controla seu próprio funcionamento e faz surgir a todo momento justificativas desse controle. Temos que nos resignar em admitir que não passam de justificativas ... Na realidade, é apenas baseada nessa possibilidade de controle que podem surgir todas as ideologias, as filosofias, as metafísicas, as religiões, que fornecem uma certa imagem capaz de polarizar essa possibilidade de controle do funcionamento.

Foucault (p.617) acrescenta ainda:

Os burocratas, eles é que são humanistas. A tecnocracia é uma forma de humanismo. Eles consideram, com efeito, que são os únicos a deter o 
jogo de cartas que permite definir o que é a "felicidade dos homens" e o modo de realizá-la.

E, finalmente, uma convicção tanto teórica como pessoal do pensador francês: "ora, eu não creio que a noção de felicidade seja verdadeiramente pensável. A felicidade não existe, a felicidade humana ainda menos" (p.618).

Esses fragmentos, ainda que muito gerais, são suficientes: para o Foucault da arqueologia, a política é tarefa funcional de controle e, na sua visão, a ética é tão-somente uma conseqüência imaginária da lógica do controle do funcionamento econômico-social, fundada na perspectiva, cínica ou ingênua, dos tecnocratas e assemelhados, que fingem ou acreditam agir em nome do bem comum. A promessa de um mundo melhor ou de forma de vida capaz de alterar o espaço público, na perspectiva sistêmica adotada então por Foucault, fica minimizada a pequenos e periféricos aspectos da existência: "pode-se definir o ótimo do funcionamento social obtendo-se, graças a uma certa relação entre aumento demográfico, consumo, liberdade individual, possibilidade de prazer ... [o que é] definido de maneira interna" (p.617). Em nenhum momento, observe-se, Foucault concede qualquer espaço para qualquer espécie de atributo humano ou qualidade humana como ensejo para se fundamentar a reflexão no plano da política e da ética. Efeito da lógica interna do campo estrutural, o sujeito, tal como Foucault o concebe nesse momento, é um efeito de superfície, é espuma que reverbera a força das ondas, é decorrência da influência de algo que o constitui e secreta seu pensamento e sua vida. $\mathrm{O}$ cogito vem a ser substituído, na forma contemporânea, pelo ça pense, e só restaria descrever o processo de constituição do je pelo ça. Aí sim, temos a noção verdadeiramente contemporânea de sujeito, entendido como tramado e constituído pela ação da estrutura, que sobredetermina o sujeito, até mesmo em termos políticos. Nada mais distante do pensamento de Foucault, nesse momento, do que a crença de que seria possível transformar o mundo por meio de um ato de vontade, individual ou coletivo, motivado pela consciência humana. ${ }^{2}$

No início dos anos 70, Foucault muda de perspectiva: procura discernir os procedimentos inerentes às relações entre saber e poder, num projeto que, apesar de prioritariamente epistemológico, tem que se amparar numa nova concepção de poder, que Foucault entende que deve ser (re)criada, pela insuficiência das teorias do poder tradicionais, sejam as ver-

2 As relações entre sujeito e estrutura podem ser elucidadas em Foucault, 1994, v.1, p.513-8. 
sões liberais, sejam as versões marxistas. A razão pela qual Foucault desconsidera as teorias do poder tradicionalmente admitidas é que elas acabam por constituir uma visão do que seria um poder legítimo, quais seus limites e qual sua origem. A analítica do poder, com o conjunto de deslocamentos proposto por Foucault, tem por objetivo um outro tipo de visada do poder. Segundo Foucault (1994, v.3, p.532), seu problema não é prioritariamente teórico, mas sobretudo histórico e metodológico: "minha pesquisa incide nas técnicas do poder, na tecnologia do poder. Ela consiste em estudar como o poder domina e se faz obedecer. Após os séculos XVII e XIX, essa tecnologia desenvolveu-se enormemente; entretanto, nenhuma pesquisa sobre este tema foi realizada". Para tal, como se sabe, Foucault desenvolveu uma concepção nominalista do poder, na qual idéias de posse do poder, de origem do poder, de campo de ação do poder, entre outras, são substituídas pela hipótese de que o poder está disseminado por todas as partes do mundo social, numa trama complexa e heterogênea de relações de poder, na qual as resistências ao poder também tomam parte e presentificam-se.

A fase da analítica do poder (1970-1977), entretanto, é farta de relatos quanto às práticas divisórias, quanto aos procedimentos estratégicos postos em jogo pelos poderes hegemônicos, e evidencia uma predileção de Foucault pela descrição das grandes estruturas de dominação ou das instituições a elas agenciadas. Certamente, um dos motivos para essa escolha foi a riqueza do instrumental metodológico posto em jogo em trazer contribuições originais à temática do desenvolvimento das tecnologias do poder nos últimos séculos, que gerou, por sua vez, interesse e expectativas crescentes em parcelas do público acadêmico e cultivado. Apesar de sua participação pessoal em movimentos de resistência, nessa época, como o GIP, em torno da questão das prisões, entre outros, Foucault pouco escreve sobre o assunto, citando em raras passagens movimentos como os contrários à lógica consumista (como os movimentos antipoluição) e os partidários da liberdade de poder usar o próprio corpo (como os movimentos pró-aborto). ${ }^{3}$ Uma das razões para essa escassez de referências quanto às resistências ao poder, talvez, está na delimitação, nessa fase, do alcance e estatuto das lutas de resistência, nas quais os indivíduos pouco ou nada tem a fazer. Antes disso, a tese de Foucault, na analítica, é a de que: "o que me parece característico da forma de controle atual é o fato de que ele se exerce sobre cada indivíduo: um controle que

3 Cf. Foucault, 1994, v.2, p.663-4. 
nos fabrica, impondo-nos uma individualidade, uma identidade" (Foucault, 1994, p.662). Essa convicção foucaultiana é categórica:

creio que, hoje, a individualidade é completamente controlada pelo poder e que nós somos individualizados, no fundo, pelo próprio poder. Dizendo de outro modo, eu não creio que a individualização se oponha ao poder, mas, pelo contrário, eu diria que nossa individualidade, a identidade obrigatória de cada um é efeito e instrumento do poder, e o que este mais teme é: a força e a violência dos grupos. (ibidem, p.663)

Essa oposição entre grupo e poder, entretanto, não é nada simples; pois nem toda luta levantada pelos grupos sociais é, efetivamente, luta de resistência ao poder. A oposição grupo versus poder somente pode ser compreendida após uma série de ressalvas levantadas na época por Foucault. Vamos enumerar, apenas de passagem, algumas: a primeira delas, talvez a mais importante, vem da constatação, decorrente de suas pesquisas históricas, de que muitas lutas supostamente contestadoras seriam, desde seu início, lutas visando à inclusão e/ou legitimação na ordem estabelecida: seria o caso das lutas pelo direito à habitação, saúde, higiene etc., que acabam consolidando as estruturas do poder e auxiliando no desenvolvimento de suas técnicas de individuação. A segunda, o fato reconhecido de que toda luta acaba sendo assimilada, ao fim e ao cabo, pelas malhas do poder. A terceira, sua descrença no potencial transformador e revolucionário dos partidos e grupos políticos; antes disso, para Foucault, a luta partidária, nos moldes secularmente praticados, nada mais é do que um sinal da extraordinária esterilidade política de nosso tempo.

Ademais, para Foucault, as lutas desenvolvidas pelos "grupos sociais organizados" podem escamotear, decididamente, procedimentos e técnicas de manipulação das massas, fenômeno bastante conhecido a partir dos episódios de movimentos de massa tão característicos do século XX, em especial no campo político. Essas técnicas de manipulação de grandes contingentes de seres humanos, lembra Foucault, não são específicas dos regimes autoritários; no nosso tempo, vivem em todos os lugares, até mesmo nos países reconhecidos como democráticos. Quem, no fim das contas, para Foucault, desenvolveu de forma mais cabal e eficaz as técnicas de normalização dos indivíduos, senão os sistemas políticos inspirados nas diversas versões do liberalismo?

Foucault, todavia, deu um novo sentido às suas interrogações, a partir de 1978, ao deparar com uma série de fatos muito marcantes à época, tais como o movimento iniciado pelo Sindicato Solidariedade (Polônia) 
e, sobretudo, a revolução iraniana. Nesse momento, Foucault entrevê que, sob certas condições, a força dos grupos tem o potencial de contestar os sistemas hegemônicos de poder e de ter êxito em modificálos, quando opera e age segundo métodos e motivos inusitados, como foi o caso da revolução iraniana. Os mais atentos à biografia de Foucault sabem que, durante um bom tempo, o pensador francês esteve no Irã e escreveu uma série de matérias sobre os acontecimentos que levaram à queda do regime do Xá Reza Pahlevi. Numa de suas reportagens, de 1978, Foucault (1994, v.3, p.716) lembra que a luta no Irã não se dirigiu nem afetou apenas ao inimigo direto, isto é, à ditadura do Xá, mas também a todo o jogo de forças externo ligado ao caso iraniano: "não se trata de uma sublevação espontânea à qual falta uma organização política: é um movimento para se livrar, ao mesmo tempo, da dominação vinda do exterior e da política interna". Foucault vai além e afirma, categoricamente, que o movimento de libertação iraniano tinha a força de pôr em xeque a lógica interna das estruturas de poder mundiais: "é a insurreição dos homens de mãos nuas que querem levantar o formidável fardo que pesa sobre cada um de nós, mas mais particularmente sobre eles, os trabalhadores de petróleo, os camponeses nas fronteiras dos impérios: o fardo da ordem do mundo inteiro. Ela é, talvez, a primeira grande insurreição contra os sistemas planetários, a forma mais moderna de revolta e a mais louca" (Foucault, 1994). Os impasses e a perplexidade gerados pela insurreição iraniana vieram do fato de ela pôr em questão todo o jogo estratégico e todo o modo de vida da nova ordem econômica mundial. Deixemos de lado a pertinência ou não na análise foucaultiana no caso do Irã, se sua avaliação era correta ou incorreta; o que deve ser ressaltado é a guinada no espírito que anima seu trabalho teórico: a possibilidade de transformação do mundo por intermédio de práticas contestadoras.

Esse é o problema que anima o último Foucault (1978-1984), que dá quiçá continuidade a questões abertas na analítica do poder, mas com um acento que é todo outro. Ele passa a estudar o papel das resistências, em todas as suas dimensões, na trama complexa das relações de poder na atualidade, seus antecedentes históricos e suas perspectivas de êxito. Seu interesse passa a ser os combates e as lutas inerentes às relações de poder, e não a descrição das grandes articulações institucionais e políticas que formam as grandes estruturas de poder e que persistem num largo espaço de tempo. Desde então, Foucault, passa a considerar que as resistências ao poder devem ser entendidas como aquelas que visam à defesa da liberdade. E aqui cabe chamar a atenção: nada mais diferente daquilo que comparece em suas fases iniciais, em que os indivíduos pouco ou nada têm a fazer nas lutas de transformação do mundo social e político. No 
último Foucault, restauram-se o lugar e o papel dos indivíduos, dos indivíduos éticos, sensíveis e racionais, no quadro das lutas políticas. Em todo caso, é o indivíduo, ontologicamente considerado, que é livre porque sente, pensa e age: "a liberdade é a condição ontológica da ética. Mas a ética é a forma refletida que a liberdade assume" (Foucault, 1994, v.4, p.712). O índice da liberdade, todavia, não é para ser entendido como uma petição de princípio meramente teórica; deve ser elucidado no plano das lutas sociais, precárias, contingentes, móveis. O campo da liberdade é o da práxis, é o da ética encarnada:

o que eu quero analisar são práticas, é a lógica imanente à prática, são as estratégias que sustentam a lógica dessas práticas e, por conseguinte, a maneira pela qual os indivíduos, livremente, em suas lutas, em seus afrontamentos, em seus projetos, constituem-se como sujeitos de suas práticas ou recusam, pelo contrário, as práticas que se lhes são propostas. Eu acredito solidamente na liberdade humana. (ibidem, p.693)

O esforço de Foucault (1994, v.4, p.721), como se pode ver, é o de se desvencilhar das críticas dos que vêem no seu trabalho um niilismo que aniquila todo espírito de luta:

nestes casos de dominação - econômica, social, institucional, ou sexual -, o problema, com efeito, é o de saber onde vai se formar a resistência ... Numa tal situação de dominação, deve-se responder a todas essas questões de um modo específico, em função do tipo e da forma precisa de dominação. Mas a afirmação, "você enxerga o poder em todo lugar; logo não existe lugar para a liberdade", parece-me absolutamente inadequada. Não se pode me atribuir a idéia de que o poder é um sistema de dominação que tudo controla e que não deixa nenhum lugar para a liberdade.

Foucault (1994, v.4, p.693), em sua última fase, quer mostrar o quanto está interessado em contribuir para o processo criativo da lutas de resistência, que constituem uma nova economia das relações de poder, pois "tudo isto está diretamente ligado a uma prática e a estratégias que são, por sua vez, móveis e se transformam”. A criatividade das estratégias e das lutas, portanto, decorrem das artimanhas da liberdade. Sua investigação, a partir desse contexto, "consiste em tomar as formas de resistência aos diferentes tipos de poder como ponto de partida" (ibidem, p.225).

Os termos da oposição entre resistência, liberdade e relações de poder são postos, por Foucault, de maneira bastante evidente: 
quando se define o exercício do poder como um modo de ação sobre a ação dos outros, quando o caracterizamos pelo "governo" dos homens uns sobre os outros - no sentido mais largo do termo - inclui-se, nesse caso, um elemento importante: a liberdade. O poder não se exerce senão sobre "sujeitos livres" e enquanto são "livres" - entendamos por isso sujeitos individuais ou coletivos que têm diante de si um campo de possibilidades no qual muitas condutas, muitas reações e diversos modos de comportamento podem ter lugar. Onde as determinações estão saturadas, não há relações de poder: a escravidão não é uma relação de poder quando o homem está acorrentado (trata-se, então, de um relação física constrangedora), mas somente quando o homem pode movimentar-se e, no limite, fugir. (Foucault, 1994, p.237-8)

Não existe luta possível entre liberdade e poder num regime de terror, nomenclatura utilizada por Foucault para designar, de maneira genérica, os regimes autoritários e burocráticos, tais como o stalinismo, o nazi-fascismo, a ditadura de Pinochet (Chile), o regime de Reza Pahlevi (Irã), o Cambodja etc. Mas a força, se impede, não constitui uma impossibilidade para a liberdade, quando ela encontra ensejo para se exercer. A liberdade, por sua condição ontológica, é insubmissa. Diz sempre não às forças que procuram, senão aprisioná-la, formatá-la e controlá-la. E o faz de modo que é necessariamente, em condições fora do terror e do constrangimento, o de um afrontamento contínuo. A liberdade somente pode se externar em um espaço público no qual estejam garantidas as condições mínimas para seu exercício, e estas somente podem ser dadas num ambiente explícito de tolerância político-social ao exercício da liberdade. Como alerta Foucault:

o problema central do poder não é o da "servidão voluntária" (como poderíamos desejar ser escravos?): no cerne da relação de poder, "induzindo-a" constantemente, temos a reatividade do querer e a "intransitividade" da liberdade. Mais que de um "antagonismo" essencial, seria melhor falar de uma "agonística" ... uma relação que é, ao mesmo tempo, de incitação recíproca e de luta; trata-se menos de uma oposição termo a termo que os bloqueia um face a outro e, bem mais, de uma provocação permanente. (ibidem)

As promessas da dialética e os sonhos do estado pleno de direito, minimizados pelo pensamento reflexivo e pelos fatos históricos, para Foucault, exigem a concepção agonística do poder como substituto inevitável. Nela, a vontade (ou o desejo) e o direito (ou a lei) tomam parte no embate, mas estão longe de se tornarem fundamentais e gerarem qualquer forma de unanimidade. O consenso, menos ainda... 
Inicialmente, na cronologia da obra de Foucault, bem entendido, a perspectiva de um tipo de luta como a de esquerda, com suas estratégias e estilo de luta muito estabelecidos, leva-o a uma posição de contestação quanto a seus efeitos, que não deixam de ser institucionais, pelo próprio fato de que os movimentos de esquerda levaram a um certo engessamento de suas estratégias, em razão de seu modo centralizador de condução. Por outro lado, as lutas de direito e pelo direito acabam por instituir um campo de luta morno e demasiado convencional. O verdadeiro campo de luta, a seu ver, é o que abre as portas a um exercício de liberdade que é autônomo, e, como tal, radical. Ainda assim, Foucault concede lugar às múltiplas modalidades de luta em jogo na atualidade. São elas, no campo dos afrontamentos e resistências ao poder (e a seus excessos): "as lutas contra a dominação (étnicas, sociais, religiosas), as lutas contra as formas de exploração (que separam o indivíduo do que ele produz), e, finalmente, as lutas que levantam a questão do estatuto do indivíduo (lutas contra o assujeitamento, contra as diversas formas de subjetividade e submissão)". ${ }^{4}$ As duas primeiras já são conhecidas de todos. A contribuição de Foucault está nas suas considerações quanto ao estatuto das lutas que levantam o estatuto do indivíduo. Elas foram elevadas por Foucault a lutas de primeira grandeza, mantendo relações circulares com as duas outras formas de luta. Longe de serem periféricas ou secundárias, as lutas em torno da individuação são as que trazem, na atualidade, questionamentos, métodos e objetivos inovadores, com efeitos que não são desprezíveis na esfera pública. As lutas individualizantes, enfim, são lutas efetivamente potentes contra as tecnologias de poder desenvolvidas na sociedade ocidental nos últimos séculos, e que têm no Estado contemporâneo um de seus principais representantes.

Para Foucault, essas são lutas de resistência contra o gigantesco aparato, técnicas e procedimentos desenvolvidos para conhecer, dirigir e controlar as vidas das pessoas, seus estilos de existência, suas maneiras de sentir, avaliar, pensar. Essas técnicas e saberes, dentro do projeto de otimização do poder, têm o objetivo explícito de conhecer e controlar a vida subjetiva de cada um dos membros submetidos aos seus campos de ação, de maneira que Foucault alerta que a técnica característica do poder moderno é dispor, simultaneamente, de técnicas totalizantes e procedimentos que visam ao "governo por individuação". O governo por individuação ou normalização, dizendo de outra maneira na terminologia de Foucault, é o substituto contemporâneo do poder pastoral desenvolvido

4 As palavras exatas a esse respeito estão em Foucault, 1994, v.4, p.227. 
no passado pela Igreja. Mas agora ele tem novos processos e conhecimentos à sua disposição: relatórios, enquetes, pesquisas e bancos de informações onde estão disponíveis dados crescentemente pormenorizados, levando a um exercício do poder que não é viável, afirma Foucault, "sem conhecer o que se passa na cabeça das pessoas, sem explorar suas almas, sem forçá-las a revelar seus segredos mais íntimos" (1994, p.229). Essa técnica do poder pretende conhecer a consciência das pessoas, com o objetivo de dirigi-las. O resultado desse processo de controle nada mais é do que o sujeito assujeitado a normas e padrões de constituição de sua subjetividade, e auto-identificado por meio de regras previamente perpetradas de conduta. Trata-se, nesse caso, do indivíduo condicionado e autocondicionado, do bom moço instituído nos padrões individualistas do modo de vida, para dar um exemplo ocidental, regido pela moralidade capitalista e seu paradigma do modo de ser burguês.

Contrapondo-se a essa realidade normalizadora das técnicas de conhecimento e de controle das subjetividades, Foucault entende que as lutas de resistência em torno do estatuto da individuação podem ser sintetizadas pela palavra de ordem seguinte: "sem dúvida, o objetivo principal, hoje, não é o de descobrirmos, mas o de nos recusarmos a ser o que somos" (ibidem, p.232). De tal modo que o problema não está tãosomente no Estado e nas suas instituições, mas sobretudo na própria esfera subjetiva, onde eles têm uma influência produtiva de aniquilação do moto próprio da condição livre. A questão, assim, é produzir, criar, inventar novos modos de subjetividade, novos estilos de vida, novos vínculos e laços comunitários, para além das formas de vida empobrecidas e individualistas implantadas pelas modernas técnicas e relações de poder.

As lutas de resistência, no caso particular da individuação, são lutas pela autonomia e emancipação. Exigem, para tal, um trabalho contínuo e sem descanso de afrontamento dos processos de autonomização contra as técnicas de individuação e normalização. Exigem, pois, uma agonística na esfera subjetiva, de valor tanto político, como também ético. Um trabalho de transformação que Foucault entende se fundamentar, verdadeiramente, nos termos da visão kantiana do esclarecimento. A Auflärung, para Foucault, antes de designar uma etapa da história, é uma atitude racional, ética e política, uma "atitude de modernidade", 5 na qual são exigidos

\footnotetext{
5 A definição de "atitude de modernidade" é a seguinte: "por atitude, quero dizer, um modo de relação ante a atualidade; uma escolha voluntária que é feita por alguns; enfim, é uma maneira de pensar e de sentir, assim como uma maneira de agir e de se conduzir, que, tudo ao mesmo tempo, marca um pertencimento e se apresenta como uma tarefa" (Foucault, 1994, v.4, p.568).
} 
o diagnóstico do tempo presente e a realização da infinita tarefa de libertação (entendida como a passagem para a maioridade, ou melhor, para uma vida crescentemente desvinculada de guias, tutores e autoridades que controlariam a consciência e a esfera subjetiva).

O topos ao qual se poderia chegar a partir das lutas de resistência, desse modo, seria a governabilidade, ou seja, o autogoverno dos indivíduos livres e autônomos. Uma autonomia a ser considerada numa esfera pública não restritiva, dependente apenas do grau de autonomia e liberdade de cada um dos membros da comunidade e da sociedade. Espaço público, bem entendido, conquistado passo a passo pela recriação e reinvenção constantes de novas formas de sociabilidade e novos estilos de existência. Heterotopia foucaultiana, esse ideal de espaço público pressupõe a presença de uma permanente agonística do mundo subjetivo e social. O que pressupõe, ainda assim, na interpretação de Foucault da idéia de esclarecimento de Kant, limites advindos da própria realização da autonomia, na qual devem conviver razão pública e razão privada. Essa condição torna-se, no pensamento político do pensador francês, absolutamente indispensável, senão a realização de um espaço público livre e democrático continuaria a ser uma mera impostura.

Curioso desenvolvimento teórico, pelas conseqüências na práxis, pois para Foucault (1994, v.4, p.226), as lutas de resistência, que se destinam à libertação e à autonomia, pelo fato de que "não procuram o (inimigo número um), mas o inimigo imediato", por não terem um objetivo futuro definitivo a alcançar, definem-se, claramente, como "lutas anárquicas" (ibidem). São elas que podem realizar, stricto sensu, o ideal de liberdade, autonomia e autogoverno. O futuro das lutas políticas e da reflexão ética, para Foucault, portanto, vive nos movimentos verdadeiramente inovadores e criativos da atualidade, os únicos dignos da modernidade: os diferentes tipos de anarquismo, cada vez mais presentes nos movimentos políticos ativos do fim do século XX. 
C. BRANCO, G. The resistance to power in Michel Foucault. Trans/Form/Ação (São Paulo), v.24, p.237-248, 2001.

- ABSTRACT: Not much studied; the last stage of Michel Foucault's thought brings important contributions to the ethic and politic debate of our time, especially because it emphasizes the roll of the individual and of collectivities in the struggles for the transformation of the actual power structures. The way the struggles for resistance are, and their importance in the framework of the last Foucault reveal a political dimension that before was unsuspected in his work. This dimension, more than the analytic of power, grants for the small and multiple movements of contestation an important and decisive roll for the future of the socio-political life, away from the scheduled frame of the political parties established and from the way of action instituted. This makes us retake, from new theoretical references, the discussion about the revolutionary potential still possible nowadays.

- KEYWORDS: Resistance; power; liberty; Foucault; contemporary philosophy.

\section{Referências bibliográficas}

CASTElO BRANCO, G., BAÊTA NEVES, L. F. (Org.) Michel Foucault: da arqueologia do saber à estética da existência. Rio de Janeiro: Nau, 1999.

ERIBON, D. Michel Foucault. Paris: Flammarion, 1991.

FOUCAULT, M. Les mots et les choses. Paris: Gallimard, 1966. . Surveiller et punir. Paris: Gallimard, 1975. . Dits et écrits. Paris: Gallimard, 1994. 4v.

HAN, B. L'ontologie manquée de Michel Foucault. Grenoble: Jérôme Millon, 1998.

MACHADO, R. Ciência e saber. A trajetória da arqueologia de Foucault. Rio de Janeiro: Graal, 1982.

ORTEGA, F. Amizade e estética da existência em Foucault. Rio de Janeiro: Graal, 1999.

RAJCHMAN, J. Foucault: a liberdade da filosofia. Rio de Janeiro: Jorge Zahar, 1987.

TERNES, J. Michel Foucault e a idade do homem. Goiânia: Editora da UCG, 1998. 